\title{
Factors Associated with Psychological Health Issues in Diploma Nursing Students: A Cross-sectional Study
}

\section{Li Kai 1,2}

1 Staff Nurse, Operating Room, Stomatological Hospital of Chongqing Medical University, China

2 Nursing Lecturer, Chongqing Medical and Health College, China

\section{Article Info}

\section{Article History:}

Submit August 28th, 2020

Accepted Sept 18th, 2020

Published Sept 30th 2020

\section{Keywords:}

Diploma nursing students; Psychological health; The Symptom Checklist

\begin{abstract}
Psychological health is the expression of harmonic, expression of human personality, and is often disrupted by multiple factors. The aim of this study is to assess psychological health status and its associated factors among diploma nursing students. A cross-sectional study design was employed. The sample comprised 542 nursing students attending this anonymous survey by completed The Symptom Checklist 90 questionnaire. Descriptive statistics and logistic regression analysis were attempted to analyze overall data. The positive rate of psychological symptoms of diploma nursing students is 20.9\%; the total score of SCL-90 and the scores of each factor are higher than the national norm; grade, personality, number of friends, parenting style, love experience, whether it is an only child, and physical exercise are influential. The main factors of the mental health status of secondary vocational nursing students. The contribution of Emotional Intelligence and Spirituality is crucial to the acquisition of well-being, happiness and meaning in life.
\end{abstract}

\section{INTRODUCTION}

Admission to a professional program marks the beginning of fulfilling a career goal. Student life is characterized as the intermediate from adolescence to adulthood. They usually live alone and away from the family home and begin to bond with their peers who often come from other places. ${ }^{1}$ They, therefore, are leaving behind a safe and controlled environment of the family and their surroundings and come into contact with different habits and perceptions, while still possessing many of the adolescence features, are experiencing a process of moving away from the family environment. $^{2}$ However, the rigors of professional education can be demanding. Stress, depression, and anxiety (SDA) can interfere with learning, affect academic performance, and impair clinical practice performance. $^{3}$

During their studies, some individuals can experience mental difficulties that are related to their inability to leave their family in combination with the feeling of loneliness and difficulties to create relationships in a new environment. The ability of the individual to live alone reflects his or her emotional maturity and is the foundation for achieving autonomy. ${ }^{4}$ Finally, a significant risk to students 'mental health is the intense feeling of insecurity regarding

Corresponding author:

Li Kai

jeffli08@163.com

South East Asia Nursing Research, Vol 2 No 3, September 2020

ISSN:2685-032X

DOI: https://doi.org/10.26714/seanr.2.3.2020.117-122 
their financial and occupational rehabilitation. The high levels of unemployment, the financial crisis, the lack of recognition in some cases of qualification lead to discouragement and the creation of intense feelings of anxiety, insecurity and even mental disorders manifested by symptoms such as insomnia, shortness of breath, eating disorders and difficulties in concentration and organization. ${ }^{5}$ Then students often develop dysfunctional ways of managing these problems, so their selfimage is affected, and they are experiencing feelings such as depression and anxiety. ${ }^{6,7}$ The existence of some mental disorder in the student has a more significant impact than on other groups in the general population as it affects his health, interpersonal relationships and academic performance. ${ }^{8}$ Inappropriate diagnosis and treatment of these problems lead to chronicity and relapses, increasing the risk of discontinuation of studies and manifestation of future occupational distress syndrome. ${ }^{9}$

Strengthening the mental health education of diploma nursing students has become a consensus in the higher education field. ${ }^{10}$ This research has investigated diploma nursing students as the research object, understood the mental health and its influencing factors, and provided psychological basis for the education and management among diploma nursing students more effectively.

This study aims to assess psychological health status among diploma nursing students and to highlight its' related factors.

\section{METHODS}

A cross-sectional study design was applied in this study. A stratified cluster random sampling method was adopted to randomly select 4 students in each of the first and second-year as the research participants.

\section{Participants \& Settings}

A total of 550 students from Chongqing Medical and Health College were voluntary recruited. This study was approved by the Ethics Committee of the Thessaly University according to the ethical guidelines of the Declaration of Helsinki. In addition, a written consent of the Students to participate in the process was obtained and they were each given an increasing serial number to ensure their anonymity.

\section{Instrument}

A self-reported questionnaire of the Symptom Checklist 90 (SCL-90) was used to collect the data. ${ }^{11}$ The scale has 90 evaluation items and contains a total of 10 factors, such as: somatization, obsessivecompulsive symptoms, interpersonal sensitivity, depression, anxiety, hostility, terror, paranoia, psychosis and others. Each item adopts a five-level scoring system (1-5 point), 1 point means no such symptoms, 2 point means mild symptoms, higher scores, more severe symptoms, 5 point means most severe symptoms. Scoring to the survey consists of two elements, such as the total score and the factor score. The total scores of 90 items are indicating the overall level of mental health which is divided into higher and lower level of mental health. Factor score, the total score of each item that makes up a factor/the number of items that make up a factor. The high score of a factor indicates the seriousness of the mental health problem of items among factors. If a factor score $\geq 2$, consider screening for positive symptoms. ${ }^{12}$ In addition, the research team also designed a general survey form on its own, including gender, age, source of birth, physical exercise, etc.

The survey method adopts an anonymous questionnaire survey in class units, with trained professionals serving as investigators. The questionnaires are uniformly distributed and recovered. The survey process uses uniform methods and instructions. The students complete the 
questionnaire carefully and independently according to the actual situation, on the spot Answer, collect and check on the spot.

\section{Statistical Analysis}

A logical regression analysis was used to carefully examine and minimizing error for all data entry by using Epidata 3.02 software. Two-person entry was attempted to establish a database to verify the accuracy of the entry. SPSS version 13.0 statistical software was utilized for data analysis.

\section{RESULTS}

\section{Participants' characteristics}

Initially, a total of 560 questionnaires was distributed. In the final stage, 550 questionnaires were returned, with a recovery rate of $98.2 \%$. The valid questionnaires included in the statistics was 542 , with an effective rate of $98.5 \%$. Among them, $280(51.7 \%)$ were in the first year, and 262 (48.3\%) were in the second year; the youngest was 15 years old and the oldest was 23 years old, with an average age of $16.67 \pm 2.78$ years old; the survey subjects were all female nursing students.

\section{The Overall SCL-90 Result}

The survey results of the overall scores of SCL-90 measurements show that the positive rate of psychological symptoms in diploma nursing students is $20.9 \%$. Furthermore, the percentages of positive symptoms for each factor such as: obsessive-compulsive symptoms (19.1\%), depression (10.8\%), interpersonal relations sensitive (8.9\%), anxiety (7.1\%), hostility and paranoia $(5.5 \%)$, psychosis $(4.7 \%)$, somatization $(3.6 \%)$, and terror $(2.0 \%)$.

\section{Comparison of Each Symptom Factor of SCL-90 With the National Norm}

It can be seen from Table 1 . that the total scores of SCL-90 and the scores of various factors of diploma nursing students are higher than the national norm, and the differences are statistically significant $(\mathrm{p}<0.05)$.

\section{Logistic regression analysis of factors affecting the mental health of secondary vocational nursing students}

In order to understand the factors that affect the mental health of secondary vocational nursing students, we take whether the subjects have mental health problems as the dependent variable, and take the grade, personality, parental education level, parental rearing style, smoking, drinking, etc. Fifteen variables were used as independent variables for quantification (personality is a multicategory variable, 3 dummy variables are set, and the remaining 14 variables are binary and rank variables). Logistic regression is introduced, and the regression equation is established by stepwise forward $\mathrm{P} \leq 0.05$ is used as the criterion for entering the equation, and finally there are 7 variables entering the regression equation. Autocratic parenting style, only child and love experience are risk factors that affect mental health. See Table 2. 
Table 1

Comparison of SCL-90 factor evaluation results of secondary vocational nursing students with domestic norms $(n=550)$

\begin{tabular}{lcccc}
\hline \multicolumn{1}{c}{ Indicators } & $\begin{array}{c}\text { Diploma Nursing } \\
\text { Student }\end{array}$ & National Norm & $\mathrm{t}$ & $\mathrm{p}$ \\
\hline Somatization & $1.45 \pm 0.29$ & $1.37 \pm 0.48$ & 11.424 & 0.022 \\
Obsessive-compulsive symptoms & $1.71 \pm 0.54$ & $1.62 \pm 0.58$ & 0.046 & 0.020 \\
Interpersonal sensitivity & $1.76 \pm 0.58$ & $1.65 \pm 0.51$ & 9.336 & 0.000 \\
Depression & $1.64 \pm 0.53$ & $1.50 \pm 0.59$ & 2.297 & 0.000 \\
Anxiety & $1.44 \pm 0.42$ & $1.39 \pm 0.43$ & 2.212 & 0.027 \\
Hostility & $1.59 \pm 0.42$ & $1.48 \pm 0.56$ & 9.505 & 0.000 \\
Terror & $1.30 \pm 0.34$ & $1.23 \pm 0.41$ & 1.339 & 0.031 \\
Paranoid & $1.51 \pm 0.38$ & $1.43 \pm 0.57$ & 8.246 & 0.020 \\
Psychotic & $1.37 \pm 0.40$ & $1.29 \pm 0.42$ & 0.064 & 0.019 \\
Total Score & $136.47 \pm 33.61$ & $129.96 \pm 38.76$ & 4.971 & 0.038 \\
\hline
\end{tabular}

Table 2

Logistic Regression Analysis of Influencing Factors of Suicidal Ideation in Diploma Nursing Students ( $\mathrm{n}=550)$

\begin{tabular}{llcc}
\hline \multicolumn{1}{c}{ Variables } & \multicolumn{1}{c}{ Assignment } & B & $p$ \\
\hline Grade/years & First year=1, Second year=2 & -0.536 & 0.000 \\
Characters & Introvert=1, Neutral=2, extrovert=3 & -0.274 & 0.000 \\
Parenting Styles & Democracy=1, Despotism=2 & 0.760 & 0.002 \\
Love Experiences & No=1, Yes=2 & 0.793 & 0.000 \\
Single children & No=1, Yes=2 & 0.833 & 0.000 \\
$\begin{array}{l}\text { Physical activity in } \\
\text { a week }\end{array}$ & $\begin{array}{l}\text { times=1, 1times=2, ,2 times=3, 3 times=4, 4 } \\
\text { times=5, 5times=6, 6times and above=7 }\end{array}$ & -0.227 & 0.000 \\
\hline
\end{tabular}

\section{DISCUSSIONS}

The survey results show that the positive detection rate of psychological problems in diploma nursing students is $20.9 \%$, which is similar to the results of other relevant domestic studies, and the total score of SCL90 and the scores of all factors are higher than the national norm..$^{13}$ and psychological status of diploma nursing students is not optimistic. Technical diploma students are a special group, most of them are eliminated from the senior high school entrance examination. If the teacher does not properly guide them, it will be difficult for them to get rid of the shadow caused by the unsatisfactory advancement. In addition, there are some incorrect public opinions in the society under diploma schools are not promising and any students enter diploma schools in a helpless mood. Most of the students are in their adolescence, which are at the stage of life when they are sensitive to external stimuli and psychological changes are the most complicated. They are more likely to experience negative emotions.

\section{Factors affecting the mental health of diploma nursing students}

Different grades of diploma students' mental health status have different survey results. The survey results show that firstyear students face more psychological problems than second-year students. The first-year students have just experienced the failure of the senior high school entrance examination. Some people choose the secondary vocational health school due to the pressure of their families. Moreover, they have just entered the school and cannot fully adapt to the new school environment and new interpersonal relationships. Therefore, the first-year 
students It is more prone to psychological problems. Introverted students are more prone to psychological problems. Compared with extroverts, introverts are withdrawn, pessimistic and cautious. They tend to have low self-evaluation and lack of selfconfidence. They often adopt evasive, selfblame, and fantasy coping styles in the face of stress, so they are prone to psychological problems; Extroverts have a wide range of communication, many friends, are good at seeking help, have a better social support network, and can respond appropriately in a passionate situation. Therefore, their psychological condition is better. ${ }^{14}$

Family factors are also the main factors influencing the psychological status of diploma nursing students. ${ }^{15}$ Democratic parenting is more conducive to the healthy growth of children's mental health than autocratic parenting. Diploma nursing students are in their adolescence, and their personal independence consciousness is developing rapidly. Democratic parenting methods give their children certain autonomy and positive and correct guidance, which is conducive to the formation of positive personality characteristics for children, and good personality characteristics are conducive to the formation of healthy psychology. Autocratic parenting methods will lead to unstable personality characteristics of children, which is extremely detrimental to children's mental health. ${ }^{16}$ The mental health of only children is worse than that of non-only children. The only child has a strong sense of self, and has poor ability to take care of themselves in life. They cannot adapt well to living in school and are prone to bad emotional experiences.

Diploma students with love experience face more psychological problems than those without love experience. The sexual consciousness of vocational students in adolescence is quickly awakened and they are prone to premature love. However, due to their lack of social experience, their understanding of themselves and others is not comprehensive enough, they often have unrealistic ideas about the future, and are more susceptible to emotional frustration, leading to anxiety, depression and other emotions. The results of this survey also found that the mental health of people who regularly participate in physical exercise is better than those who do not exercise regularly. This result is consistent with the research results of Wang`s paper. ${ }^{17}$ Physical exercise can clear tension, maintain friendship, make people optimistic, and improve social adaptability. Therefore, physical exercise has a good role in promoting mental health.

There are several limitations in this study, there was a relatively small number of studies included. While the heterogeneity of the studies included, in particular the methodology, sample size and location of these studies makes it more difficult to generalize the settings, concentrated on only the nursing students who had been enrolled in one college and the other is this study only focused on one direction of influence.

\section{CONCLUSION}

The results of this study indicated that the mental health status of diploma nursing students is not optimistic. The relevant departments should strengthen their mental health education work, provide psychological interventions to students with mental health problems, and regularly carry out psychological education activities to prevent problems before they occur. The contribution of Emotional Intelligence and Spirituality is crucial to the acquisition of well-being, happiness and meaning in life. It is crucial to promote cultivation with significant benefits in the course of their lives and the campus community as a whole.

\section{ACKNOWLEDGMENTS}

The researcher would like to say thank you to all respondents who participated in this research. 


\section{CONFLICTS OF INTEREST}

Neither of the authors has any conflicts of interest that would bias the findings presented here.

\section{REFERENCES}

1. Burris J, Brechting E, Salsman J, et al. Factors associated with the psychological well-being and distress of university students. J Am Coll Heal 2009; 57: 536-544.

2. Eisenberg D, Gollust SE, Golberstein E, et al. Prevalence and correlates of depression, anxiety, and suicidality among university students. Am J Orthopsychiatry 2010; 77: 534542.

3. Hoying J, Melnyk BM, Hutson E, et al. Prevalence and correlates of depression, anxiety, stress, healthy beliefs, and lifestyle behaviors in firstyear graduate health sciences students. Worldviews Evidence-Based Nurs 2020; 17: 4959.

4. Kunnanatt JT. Emotional intelligence: The new science of interpersonal effectiveness. Hum Resour Dev Q 2004; 15: 489-495.

5. Gutiérrez García RA, Amador Licona N, Sánchez Ruiz A, et al. Psychological distress, sanitary measures and health status in student's university. Nov Sci; 13. Epub ahead of print 2021. DOI: $10.21640 /$ ns.v13ie.2602.

6. Hardeman RR, Przedworski JM, Burke SE, et al. Mental well-being in first year medical students: A comparison by race and gender. $J$ Racial Ethn Heal Disparities 2015; 2: 403-413.

7. Fan Z, He S. Beijing college students' selfconsciousness: its level, structure and relationship with mental health. Wei Sheng Yan Jiu 2013; 42: 960-964.
8. Rosenzweig S, Reibel DK, Greeson JM, et al. Mindfulness-based stress reduction lowers psychological distress in medical students. Teach Learn Med 2003; 15: 88-92.

9. Watson R, Gardiner E, Hogston R, et al. A longitudinal study of stress and psychological distress in nurses and nursing students. J Clin Nurs 2009; 18: 270-278.

10. Kanji N, White A, Ernst E. Autogenic training to reduce anxiety in nursing students: Randomized controlled trial. J Adv Nurs 2006; 53: 729-735.

11. Zhou J, Yu J, Zhou Y, et al. Study of item text in the Chinese symptom checklist-90. Medicine (Baltimore) 2021; 100: e24841.

12. Wang ZH, Ye Y, Shen Z, et al. A meta-analysis of Symptom checklist-90 assessment results in Chinese nurses. Chinese J Ind Hyg Occup Dis 2018; 36: 129.

13. Zhang L, Sun H. Research on correlation between the psychological health and selfesteem level of technical secondary school student nurse. Chinese J Nurs Adm 2009; 9: 5759.

14. LuX. Relationship between personality, defense style, and mental health of technical secondary nursing students. Chinese Nurs J 2004; 18: 442443.

15. Sun H, Zhuang N, Tian Y, et al. Correlation between general self-efficacy, coping style and mental health of nursing students. Chinese J Nurs Educ 2008; 5: 243-246.

16. Zhuang N, Sun H, Wang Y, et al. Correlation research between self-efficacy, mastery and mental health of practical nurses. Chinese J Nurs Educ 2008; 14: 430-432.

17. Wang J. Correlation of self-rated health and selfefficacy of the college nursing interns or above. Tianjin J Nurs 2012; 20: 203-205. 